\title{
Research Doctorate
}

National Cancer Institute

\section{Source}

National Cancer Institute. Research Doctorate. NCI Thesaurus. Code C67144.

A doctorate nearly always awarded in recognition of academic research that is of a publishable standard (even if not actually published) and that represents at least a modest contribution to human knowledge. The research is usually assessed by submission and defense of a doctoral thesis or dissertation, though in some cases a coherent body of published literature can be accepted instead. 